\title{
Correction to: Survey of water supply and assessment of groundwater quality in the suburban communes of Selembao and Kimbanseke, Kinshasa in Democratic Republic of the Congo
}

\author{
Michel L. Kapembo ${ }^{1}$. Florent B. Mukeba ${ }^{2,3} \cdot$ Periyasamy Sivalingam $^{4} \cdot$ Johnny B. Mukoko $^{2} \cdot$ Mathieu K. Bokolo $^{1}$.
} Crispin K. Mulaji ${ }^{1} \cdot$ Pius T. Mpiana ${ }^{1}$ · John W. Poté ${ }^{1,3,5}$

Published online: 1 December 2021

(c) The Author(s) 2021

\section{Correction to: Sustainable Water Resources Management https://doi.org/10.1007/s40899-021-00592-y}

There was mistake in affiliation which is corrected through this correction.

Publisher's Note Springer Nature remains neutral with regard to jurisdictional claims in published maps and institutional affiliations.

The original article can be found online at https://doi.org/10.1007/ s40899-021-00592-y.

John W. Poté

John.Pote@unige.ch

1 Department of Chemistry, University of Kinshasa,

Faculty of Science, B.P. 190, Kinshasa XI,

Democratic Republic of the Congo

2 Department of Biology, Faculty of Science, National Pedagogical University, Kinshasa, Democratic Republic of the Congo

3 Human Science Research Center (Centre de Recherche en Sciences Humaines (CRESH)), 33, Avenue Comité Urbain, Commune de la Gombe, B.P 3474, Kinshasa/Gombe,

Democratic Republic of the Congo

4 Postgraduate and Research Department of Microbiology, Jamal Mohamed College, Tiruchirappalli,

Tamil Nadu 620020, India

5 Institute F. A. Forel and Institute of Environmental Sciences, University of Geneva, Bd Carl-Vogt 66, 1211 Geneva 4, Switzerland 